KREATIF

Jurnal Ilmiah

Prodi Manajemen Universitas Pamulang
ISSN : $2339-0689$, E-ISSN : 2406-8616

J. KREATIF, Vol. 8, No.1, Juni 2020 (Halaman 18-38)

Tersedia Online di: http://openjournal.unpam.ac.id/index.php/kreatif

\title{
PENGARUH GAYA KEPEMIMPINAN, MOTIVASI, SERTA DISIPLIN KERJA TERHADAP KINERJA KARYAWAN (Study di PT Mitsui Leasing Capital Indonesia Abdul Muis - Jakarta Pusat)
}

\author{
Ading Sunarto \\ Program Studi Manajemen Fakultas Ekonomi Universitas Pamulang \\ Email: dosen02153@unpam.ac.id
}

\begin{abstract}
ABSTRAK
Perkembangan dunia usaha saat cukup pesat, persaingan semakin kuat dan bertambah banyak terutama di bisnis yang sama, jika perusahaan ingin tetap bertahan dan tercapai visi dan misinya maka kualitas kinerja SDM adalah salah satu kunci keberhasilannya. Penelitian kuantitatif ini dilaksanakan untuk melihat pengaruh gaya kepmimpinan (X1), motivasi(X2), disiplin kerja(X3), trhadap kinerja (Y) di PT. Mitsui Leasing Capital Abdul Muis - Jakarta Pusat baik secara parsial dan simultan.

Metode yang dipakai yaitu penelitian asosiatif serta menggunakan instrument questioner yang masing-masing variable memiliki 12 pernyataan dengan jumlah populasi sekaligus dijadikan sampel sebanyak 100 responden atau menggunakan sample jenuh. Analysis data yang dipakai menggunakan regresi linear dengan bantuan aplikasi software SPSS 23.

Hasilnya pengolahan data membuktikan bahwa : 1.Gaya Kepemimpinan(X1), terdapat pengaruh positip \&signifikan pada Kinerja (Y) di PT.Mitsui Leasing Capital Indonesia Abdul Muis - Jakarta yang di buktikan dari perolehan persamaan regresi sederhana yaitu $\mathrm{Y}=13,100+0,823 \mathrm{X}_{1} 2$. Motivasi (X2), terdapat pengaruh positip \& signifikan pada KinerjaKaryawan(Y) di PT.Mitsui Leasing Capital Indonesia Abdul Muis - Jakarta Pusat yang di buktikan dari perolehan fungsi regresi sederhana yaitu $Y=8,866+0,887 \mathrm{X}_{2} 3$. Displin Kerja (X3), terdapat pengaruh positip \& signifikan pada KinerjaKaryawan(Y) di PT.Mitsui Leasing Capital Indonesia Abdul Muis - Jakart Pusata yang ddapat diketahui dari hasil persamaan regresisederhana yaitu $\mathrm{Y}=27,003+0,768 \mathrm{X}_{3}$ Dari hasil olah data tersebut perusahaan sebaiknya lebih meningkatkan kedisiplinan kerja dan integritas karyawannya untuk meningkatkan kinerja karyawannya.
\end{abstract}

Kata Kunci : Gaya Kepemimpinan; Motivasi; Disiplin Kerja Serta Kinerja

\section{ABSTRACT}

The development of the business when fast enough, the competition increasingly strong and more especially in the same business, if the company wants to survive and achieve its vision and mission, the quality of human resource performance is one of the keys to success. Quantitative research was conducted to 
see the influences of Leadership style(X1), motivations (X2), work disciplines (X3), towards Performances (Y) in PT. Mitsui Leasing Capital Abdul Muis - Central Jakarta both partially and simultaneously.

The method used is associative research as well as using instrument questioner which each variable has 12 statements with the population number as well as a sample of 100 respondents or using a saturated sample. Analysis of data used using linear regression withthe help of SPSS 23 softwares.

The resultof data processing proves that: 1) leadership Style (X1), there is a significants and positive influences on performances (Y) at PT. Mitsui Leasing Capital Indonesia Abdul Muis - Jakarta which is proved from the result of simple regression equation i.e. $Y=13.100+0,823 x 1$ 2) motivation $(X 2)$, there is a significants \& positive influences on employees performances $(Y)$ at PT. Mitsui Leasing Capital Indonesia Abdul muis - Central Jakarta which is attest from the result of simple regression equation i.e. $Y=8.866+0,887 \times 2$ 3) Displin work $(X 3)$, There is a significants \& positive influence on employees performances ( $Y$ ) at $P T$. Mitsui Leasing Capital Indonesia Abdul muis - Jakart pusata which can be seen fromthe results of simple regression equation that is $Y=27.003+0,768 \times 3$ from the result of the data of the company Should further enhance the work discipline and integrity of its employes to improve the performances of its employee.

Keywords: Leadership Style; Motivations; Work Discipline \& Performances

\section{PENDAHULUAN}

\section{A. Latar Belakang Permasalahan}

Pada dasarnya, SDM ialah orang yang dimanfaatkan tenaganya pada sebuah perusahaan sebagai motorik, sebagai manusia yang berfikir \& sebagai perencana guna menggapai visi perusahaan tersebut. Akhir-akhir ini, informasi terupdate mengatakan bahwa karyawan bukan sebagai sumber tenaga kerja saja, melainkan merupakan modal atau aset bagi suatu perusahaan, oleh sebab itu lalu dikenalah istilah teranyar diluar H.R. (Human Resourcees), yakni H.C. atau Human Capital. Disinilah Sumber Daya Manusia dipandang bukan hanya saja sebuah aset utama, melainkan aset yang mempunyai value \& dapat ditingkatkan jumlahnya, dikembangkan (membandingkan oleh portfolio investasi) serta juga bukan sebaliknya sebagai liabiliti (beban,cost). Dalam hal ini pandangan SDM sebagainvestasi bagi perusahaan lebih mengemuka. Penjelasan SDM bisa dibedakan menjadi dua, yaitu pengertian micro dan macro. Penjelasan SDM secara micro yaitu dapat dinamakan sebagai pegawai, buruh, karyawan, pekerja, tenaga kerja dan lainlain atau orang yang bekerja \& menjadi anggota dari suatu organisasi perusahaan ataupun institusi. Sementara penjelasan SDM secara macro yaitu masyarakat sebuah negara yang belum bekerja ataupun yang telah bekerja baik yang telah melewati usia pensiun.

PT.Mitsui Leasing Capital Indonesia (Mitsuileasing) yaitu suatu perusahaan yang kepunyaan sahamnya setengahnya dipunyai oleh JA Mitsui Leasing, Ltd. Jepang dan didirikan secara resmi. Usanya pembiayaan 
kendaraan bermotor melewati Pembiayaan Investasi, Pembiayaan Modal Kerja, Pembiayaan Multiguna, ataupun kegiatan bisnis pembiayaan lainnya mengacu pada persetujuan OJK, serta bisnis sewa operasi (operating lease) ataupun bisnis berbasis fee selama tidak berlawanan dengan peraturan UU di sektor jasa keuangan merupakan bidang usaha Mitsui Leasing sampai saat ini. Performa Mitsui Leasing semakin tinggi setiap tahun, entah itu dalam total pendapatan ataupun pendapatan netto dan seiring dengan bergulirnya waktu, aset Mitsui Leasing juga meningkat.

Pertumbuhan dari usaha Mitsui Leasing sangat menyakinkan dan menggembirakan. Seiring dengan pertumbuhan yang cepat dan kecanggihan teknologi perusahaan, serta besarnya wilayah konsumen yang semestinya di servis, saat ini perusahana ini sudah menambah beberapa cabangnya di Jakarta, yakni Gatot Subroto,Abdul Muis,Pondok Indah,Kelapa Gading serta cabang di berbagai kota di luar Jakarta, antara lain : Serpong,Bekasi,Medan,Semarang,Surabaya,Bandung,

Denpasar,Yogyakarta,Balikpapan \& Palembang. Dalam hal ini peneliti melakukan penelitian di salah satu unit perusahaannya yakni di Cabang Abdul Muis Jakarta Pusat.

Sejalan oleh visi dari perusahaan ini yaitu ingin menjadi perusahaan pembiaya-an otomotif yang profesional serta terpercaya, didalam melakukan pengembangan bisnis, perusahana ini mempunyai misi serta komitmen untuk memberikan servis serta solusi pembiaya-an otomotif yang tepat waktu,akurat serta kreatif untuk para konsumen serta kolega bisnis, dengan mengembangkan sistem service paling bagus dengan pengembangan teknology "on-line"serta "layanan satu hari. Perkembangan usaha Mitsui Leasing yang cukup menyakinkan tersebut dapat dilihat pada profil laporan tahunan. Berbagai lapisan masyarakat dan golongan, baik perusahaan maupun perorangan merupakan konsumen dari Mitsui Leasing. Mitsui Leasing senantiasa menangani masalah Pelanggan secara profesional, cermat cepat dan memuaskan untuk memberikan Pelayanan yang terbaik dan memenuhi kebutuhan para Pelanggan maka Customer Care.

Dalam pencapaian visi dan misi perusahaan serta menentukan pencapaian kinerja karyawannya dan tentunya keuntungan perusahaan, pemimpin sebuah perusahaan merupakan sumber yang paling penting. Seorang pemimpin yang dapat mencapai visi dan misi perusahaannya serta menjadikan perusahaannya menjadi perusahaan hebat dan bisa bersaing sehat dalam dunia bisnis dan tentunya memperhatikan kemakmuran karyawannya merupakan pemimpin yang baik. Gaya Kepemimpinan adalah gabungan jati diri yang dipakai atasan dalam mempengaruhi karyawannya supaya tujuan perusahaan tergapai / dapat pula dinyatakan bahwa gaya kpemimpinan yaitu pola perilaku serta strategi yang digemari serta sering digunakan oleh seorang pimpinan, menurut Rivai (2014:42).

Hasil observasi menunjukkan bahwa pada saat karyawan sedang dalam masalah, pemimpin perusahaan jarang meluangkan waktunya untuk mendengarkan keluh kesah bawahannya. Pemimpin memperlakukan anak buahnya dengan cara yang sama namun kurang dalam mengatur pola kerjanya dan belum maksimal. 
Motivasi kerja adalah unsur yang yang harus diperhatikan didalam kepegawaian sebuah perusahaan, yang artinya bahwa karyawan harus memiliki motivasi dalam melakukan kerjanya. Karyawan yang memiliki motivasi kerja yang tinggi pastinya ingin melaksanakan pekerjaannya dengan sungguh-sungguh dengan mengerahkan semua kompetensi yang dimilikinya dalam menyelesaikan semua pekerjannya.

Dari hasil studi pendahuluan yang sudah dilakukan didapatkan informasi bahwa minimnya tingkat inisiatif dan kreativitas pegawai mengindikasikan bahwa motivasi karyawan masih rendah. Motivasi adalah hal yang melatarbelakangi karyawan untuk melakukan tujuan tertentu. Perlilaku masing-masing individu merupakan cerminan yang paling sederhana dalam memotivasi. Supaya tingkah laku pekerja sesuai dengan visi dan misi organisasi, maka perlu adanya perpaduan atau gabungan diantara motivasi akan dipenuhinya kesejahterahan mereka semua serta permintaan perusahaan.

Disiplin senantiasa menjadi suatu permasalahan dalam sebuah perusahaan, rendahnya tingkat disiplin menjadi masalah yang sering dialami dalam melakukan tugas pekerjaan sehari-hari. Dibawah ini permasalahan yang terjadi dimana di saat organisasi sedang meningkatkan program pencapaian kinerja yang berdaya guna, akan tetapi malah pada organisasi ini disiplin kerja memperlihatkan kecenderungan yang kurang optimal dari hasil observasi yang penulis lakukan,. Hal ini dapat ditunjukkan dari data Absensi pegawai di perusahaan ini dari bulan January sampai dengan bulan December 2018 berikut ini :

Tabel 1

Data Kehadiran Pegawai

PT.Mitsui LeasingCapital Indonesia Abdul Muis-Jakarta Periode January -December 2018

\begin{tabular}{|c|c|c|c|c|c|}
\hline Month & $\begin{array}{c}\text { Jumlah } \\
\text { Pegawai }\end{array}$ & $\begin{array}{c}\text { Izin } \\
\text { Sakit }\end{array}$ & Cuti & Alpa & $\begin{array}{c}\text { Terlambat } \\
\text { Dengan } \\
\text { Keterangan }\end{array}$ \\
\hline January & 102 & 10 & 5 & 16 & 20 \\
\hline Februari & 102 & 8 & 7 & 10 & 15 \\
\hline Maret & 104 & 7 & 5 & 6 & 10 \\
\hline April & 103 & 5 & 9 & 15 & 18 \\
\hline Mei & 103 & 11 & 15 & 15 & 11 \\
\hline Juni & 103 & 6 & 15 & 12 & 16 \\
\hline Juli & 102 & 14 & 18 & 17 & 12 \\
\hline Month & Jumlah & Izin & Cuti & Alpa & $\begin{array}{c}\text { Terlambat } \\
\text { Dengan }\end{array}$ \\
\hline Ageterangan \\
\hline September & 101 & 15 & 6 & 14 & 17 \\
\hline Oktober & 100 & 9 & 4 & 9 & 23 \\
\hline November & 100 & 12 & 11 & 11 & 25 \\
\hline
\end{tabular}


KREATIF : Jurnal Ilmiah Prodi Manajemen Universitas Pamulang, Volume 8, No. 1, Juni 2020

\begin{tabular}{|c|c|c|c|c|c|}
\hline December & 100 & 9 & 13 & 14 & 22 \\
\hline Jumlah & & $\mathbf{1 1 2}$ & $\mathbf{1 2 1}$ & $\mathbf{1 5 4}$ & $\mathbf{2 0 8}$ \\
\hline
\end{tabular}

Sumber : Bag Personalia PT.Mitsui Leasing CapitalIndonesia Abdul Muis - Jakarta, 2018

Berdasarkan dari data table 1.1 diatas, menunjukkan bahwa secara semuanya dalam keadaan yang tidak begitu bagus, dimana dari keseluruhan pegawai baik itu yang telat datang, izin, tanpa izin, ataupun selesai lebih awal memperlihatkan kecenderungan yang semakin tinggi, hal ini mengindikasikan masih terdapat banyak pegawai yang disiplin kerjanyanya kurang serta persentase kehadiran karyawan pada bulan Januari 2018 sampai dengan Desember 2018.

Berdasarkan dari paparan deskripsi diatas maka judul penelitian yang penulis ingin sampaikan lebih dalam yaitu : "Pengaruh Gaya Kepemimpinan, Motivasi Dan Disiplin Kerja Terhadap Kinerja Karyawan (Study pada PT. Mitsui Leasing Capital Indonesia Abdul Muis - Jakarta)".

\section{B. Perumusan Masalah}

1. Seberapa positip serta signifikan pengaruh gaya kpemimpinan di PT.Mitsui LeasingCapital Indonesia Abdul Muis -Jakarta terhadap kinerja karyawannya secara partial?

2. Seberapa positip serta signifikan pengaruh motivasi di PT.Mitsui Leasing CapitalIndonesia Abdul Muis -Jakarta terhadap kinerja karyawannya secara partial?

3. Seberapa positip serta signifikan pengaruh disiplin kerja di PT. Mitsui Leasing CapitalIndonesia Abdul Muis -Jakarta terhadap kinerja karyawannya secara partial?

4. Seberapa positif dan signifikan pengaruh gaya kpemimpinan, motivasi dan disiplin kerja di PT. Mitsui Leasing Capital Indonesia Abdul Muis - Jakarta terhadap kinerja karyawannya secara simultan?

\section{KAJIAN PUSTAKA}

\section{A. Manajemen SDM}

Sumber daya manusia merupakan satu-satunya sumber daya yang memiliki akan perasaan, keinginan,keterampilan, pengetahuan, dorongan, daya, dan karya (rasio, rasa, dan karsa) menurut Sutrisno (2016:3). Seluruh potensi SDM tsb berpengaruh kepada upaya perusahaan untuk mencapai visi dan misinya. SDM ialah individu yang bekerja serta berguna sebagai asset organisasi/perusahaan yang bisa dihitung jumlahnya(kuantitatif), dan

SDM adalah potensi yang menjadi motorik perusahaan menurut Nawawi dalam Gaol (2014:44). Bagian keilmuan yang menitikkberatkan pada permasalahan individu yang mempunyai kedudukan yang penting dalam setiap perusahaan danorganisasi merupakan pengertian dari manajemen sdm. Mustahil bagi perusahaan untuk mencapaitujuannya tanpa manusia yang mempunyai keahlian dan kompetensi maka, sumberdaya ini lah yang membuat sumber daya lain dapat berjalan. 
Daya fikir serta daya fisik setiap individu merupakan bagian dari SDM. Daya fikir dan daya fisik SDM merupakan factor penentu kemampuan setiap manusia. Di dalam setiap aktivitas yang dilakukan SDM atau individu menjadi unsur terpenting. Peralatan yang kuat atau canggih tanpa peran aktif manusia, tidak artinya sama sekali. Daya fikir ialah kecerdasan yang dibawa semenjak dilahirkan (modal dasar) sementara kecakapan didapatkan dari usaha(belajardan pelatihan). Kecerdasan tolok ukurnya Intelegence Quotient(IQ)\&Emotion Quality(EQ). Dari beberapa definisi diatas maka dapat dikatakan bahwa suatu manajemen yang berhubungan dengan perencanaan, pengorganisasian, pengarahan, dan pengawasan untuk mengembangkan dan mendayagunakan para karyawan atau sdm sedemikian rupa tercapai berbagai tujuan organisasi secara efektif dan efisien merupakan pengertian dari manajemen sdm.

\section{B. Gaya Kepemimpinan}

Mencari dan memilih seorang pemimpin yang dapat menjalankan organisasi perusahaan dengan baik bukanlah perkara yang mudah. Pengaruh gaya kepemimpinan terhadap keberhasilan sebuah bisnis sangatlah besar. Karyawan akan mempunyai produktivitas yang baik apabila memperoleh motivasi yang baik dari seorang pimpinannya. Jadi disini tidak terus harus selalu memerintah dalam pekerjaannya saja, melainkan menjalin hubungan harmonis dengan bawahannya agar tercipta lingkunngan kerja yang baik serta nyaman. Dalam pencapaian tingkat kinerja pegawai sebuah organisasi perusahaan dan profitabilitas perusahaan pemimpin sebuah perusahaan merupakan sumber yang paling penting.

Menurut Rivai (2014:42) Gaya artinya sikap, gerakan, tingkah laku, sikap yang elok, gerak-gerik yang bagus, kekuatan, kesanggupan untuk berbuat baik. Sementara gaya kpemimpinan yang merupakan sekumpulan jati diri yang dipakai atasan dalam mempengaruhi anak buahnya supaya sasaran perusahaan tercapai atau dapat pula dinyatakan bahwagaya kepimpinan merupakan polaperilaku serta srategi yang disukai \&sering dijalankan oleh seorang atasan.

Dewasa ini banyak gaya kpemimpinan yang digunakan dalam mengidentifikasi type-tipe pemimpin. Salah satunya yang biasanya dikenal adalah menyatakan bahwa pemimpin pada dasarnya dikategorikan dalam 5 tipe, yaitu : 1) Tipe Otokratic, disini bawahan hanya berperan sebagai pelaksana saja, sementara pemimpin bertindak sendiri tanpa melibatkan bawahannya. 2) Tipe aternalistik, didalam tipe ini penyelesaian pekerjaan serta

terpeliharanya hubungan yang harmonis terjalin dengan baik sebagaimana seorang ayah akan terus berusaha hubungan yang serasi dengan putranya. 3) Tipe Khariismatik, artinya bahwa pemeliharaan hubungan dengan bawahannya didasarkan kepada relasional dan bukan bertujuan kekuasaan. 4) Tipe Laissez Faire, artinya bahwa aksentuasi pada hubungan lebih diutamakan dari pada penyelesaian tugas. 5) Tipe Demokratik, tipe ini dipandang paling ideal yang tercermin dalam hal pengambilan keputusan yang cenderung memperlakukan para bawahannya sebagai rekan kerja dan orientasi hubungan yang bersifat relasional. 


\section{Motivasi}

Motivasi merupakan aktivitas perilaku yang bekerja dalam usaha memenuhi kebutuhan-kebutuhan yang diinginkan menurut Irham Fahmi (2016:190). Suatu kesenjangan atau pertentangan yang dialami antara kenyataan dengan dorongan yang ada didalam diri merupakan Teori motivasi menurut Maslow yang didasarkan pada teori kebutuhan. Karyawan akan menunjukkan perilaku kecewa apabila kebutuhan pegawai tidak terpenuhi, sebaliknya pegawai akan memperlihatkan perilaku yang gembira apabila kebutuhannya terpenuhi sebagai manifestasi dari rasa puas. Hierarki kebutuhan menurut Abraham Maslow yaitu : 1) Kbutuhan Fisiologis : seperti makan,minum,udara, perumahan dll. 2)Kebutuhan keselamatan dan keamanan : seperti keamanan kerja, uang pesangon, senioritas dll. 3)Kebutuhan rasa memiliki:seperti kebutuhan akan teman, cinta dan memiliki. 4) Kebutuhan akan harga diri : penghargaan diri, pengakuan, prestise dll. 5) Kebutuhan perwujudan diri : kecakapan, kemampuan, keterampilan dan potensi optimal, dll.

Serangkaian perilaku dan value yang mempenngaruhi individu agar mencapai hal yang spesifik sesuai dengan tujuan individu merupakan pengertian dari motivasi. Suatu kekuatan untuk mendorong seseorang berperilaku dalam mencapai tujuannya merupakan sikap dan nilai. Arah perilaku kerja (kerja untuk mencapai tujuan), dan kekuatan perilaku (sebagai kuat usaha individu dalam bekerja) merupakan dua komponen sikap dan nilai motivasi. Penilaian unik, pikiran serta experience masa lalu yangmerupakan bagian dari hubungan internal serta eksternal organisasi merupakan bagian dari motivasi.

\section{Disiplin Kerja}

Displin karyawan dalam manajemen sdm berasal dari perspektif bahwatidak ada individu yang sempurna,lepas dari kesalahan serta kekhilafan, menurut Siagian (2012:305). Sementara menurut Setiyawan (2012:189) disiplin kerja adalah "suatu bentuk ketaatan terhadap aturan, baik tertulis maupun tidak tertulis yang telah ditetapkan". Ciri dari setiap sumber daya manusia dalam organisasi diharapkan menjadi cerminan displin kerja, sebab dengan kedisplinan perusahaan akan berjalan dengan baik serta bisa mencapai tujuannya dengan bagus pula. Kesadaran serta kesediaan

seseorang menaati peraturan semua perusahaan dan aturan sosial yang berlakumerupakan suatu cerminan dari disiplin.. Sementara sikap individu yang secara sukarela mentaati semua peraturan dan sadar akan tugas dan tanggung jawabnya yaitu arti kesadaran. Dorongan semangat kerja agar berkinerja dengan optimal akan terpacu dengan adanya disiplin yang tinggi sesuai dengan yang diinginkan organsiasi. Hal ini sejalan dengan gagasan Hasibuan (2012:194)dimana disampaikan bahwa "Kesadaran dan kesediaan seseorang menaati semua peraturan perusahaan dan norma-norma sosial yang berlaku merupakan pengertian Disiplin".

Dari beberapa penjelasan disiplin tersebut diatas dapat dijelaskan bahwa suatu bentuk cara karyawanyang ingin memperbaiki serta membentuk 
pengetahuan,sikap serta perilaku karyawan sehingga perilaku karyawantersebut secara sukarela berusaha bekerja secarakoperatif dengan para pegawai lain serta meningkatkan prestasi kerja merupakan definisi dari displin kerja.

\section{E. Kinerja}

Kinerja awal mulanya dari kata Job Performance / Actual Performance(prestasi kerja atau prestasi sesuangguhnya yang dicapai oleh seseorang) itu menurut Mangkunegara (2013:67). Dengan kata lain hasil kerja secara kualitas \& kuantitas yang digapai oleh seorang karyawan didalam menjalankan tugasnya dan tanggungjawabnya sesuai dengan tanggungjawab yang diberikan kepadanya merupakan pengertian kinerja. Sementara menurut Marwansyah (2010:228) kinerja yaitu pencapaian atau prestasi individu berkenaan dengan tugasn - tugas yang didapatnya kepadanya. Sedangkan menurut Barnawi dan Arifin (2012:12), "hasil kerja yang dicapai oleh seseorang atau kelompok orang dalam suatu organisasi, sesuai dengan wewenang dan tanggung jawab masing-masing dalam mencapai upaya mencapai tujuan organisasi bersangkutan secara legal, tidak melanggar hukum, dan sesuai dengan moral maupun etika merupakan pengertian dari kinerja”.

Karyawan yangdapat berkinerja dengan baik merupakan harapan dari setiap perusahaan. Didalam penilaian kinerja, informasi mengenai kinerja karyawan dapat kita peroleh. Seseorang karyawan dapatbekerja dengan optimal ataupun tidak yang dilihat dari kategori penilaian yang dibandingkan antara tolak ukur penilaiankinerja organsiasi dengan kinerja pegawai dapat diketahui dari hasil evaluasi kinerja karyawan. Dengan demikian dapat dartikan bahwa indikasi bahwa kinerjakaryawan tersebut mampu memenuhi harapan kinerja organsiasi atau tidak dapat dilihat dari penilaian kinerja yang semakin tinggi.

\section{F. Kerangka Pemikiran}

Paradigma konseptualmengenai bagaimana teory berhubungan dengan barbagai faktor yang telah didentifikasi sebagai masalah yang penting merupakan pengertian dari kerangka berfikir menurut Sugiyono (2009:388).

Kerangka pemikiran perlu disusun dalam rangka memberikan arahan agar penelitian yang dilakukan agar sesuai dengan yang telah digariskan dari latar belakang, perumusan masalah. Kerangka pemikiran berikut ini memberikan gambaran tentang pengaruh gaya kepemimpinan(X1), motivasi(X2), dan disiplin kerja(X3)terhadap kinerja karyawan(Y), dimana inputnya yaitu visi, misi perusahaan, SDM, sarana dan prasarana perusahaan, lalu prosesnya yaitu indikator dari variabel gaya kepemimpinan (X1),motivasi (X2), dan disiplin kerja (X3)dan kemudian outcomenya yaitu indikator dari variabel kinerja karyawan(Y).

\section{G. Model Penelitian}

Kerangka berpikir adalah model konseptual mengenai bagaimana teori mempunyai korelasi dengan barbagai faktor yang sudah didentifikasi sebagai 
masalah yangpenting menurut Sugiyono (2009:388). Kerangka pemikiran perlu disusun dalam rangka memberikan arahan supaya penelitian yang dikemukakan agar sesuai dengan yang telah digariskan dari latar belakang, perumusan masalah. Kerangka pemikiran berikut ini memberikan gambaran tentang pengaruh gaya kepemimpinan, motivasi, dan disiplin kerja terhadap kinerja karyawan. Secara skematis, kerangka berfikir yang digunakan dalam penelitian ini yaitu sebagai berikut :

Gambar I

Model Penelitian

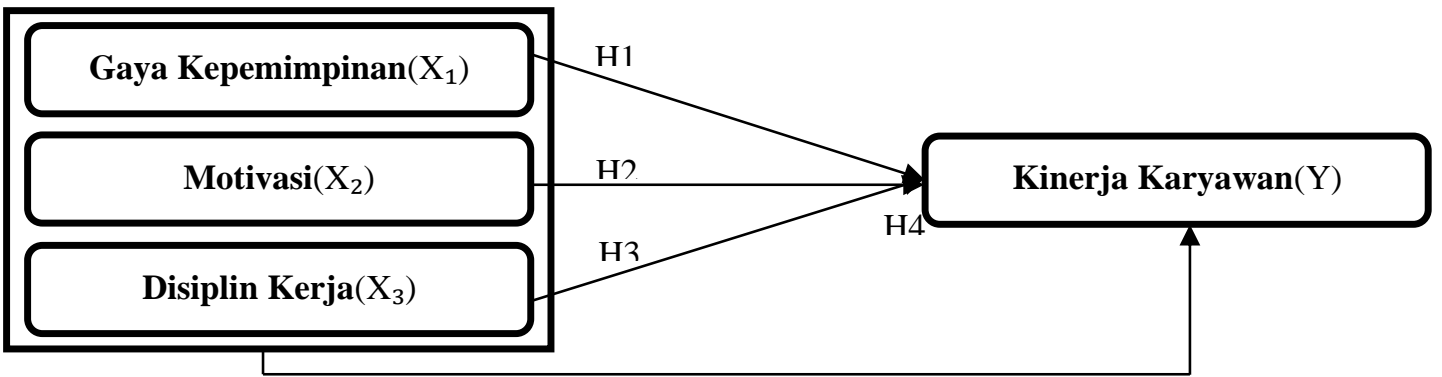

\section{H. Hipotesis}

Hipotesys ialah jawaban sementara pada rumusan permasalahan penelitian menurut Sugiyono (2009:70). Rumusan masalah ini dinyatakan dalam bentuk kalimat hipotesys dalam penelitian ini. Hipotesis penelitian yang peneliti kemukakan yaitu :

1. Pengaruh Gaya Kepemimpinan (X1) terhadap Kinerja Pegawai (Y)

Hipotesys1(H1) : Di asumsikan ada pengaruh signifikan Gaya Kepemimpinan(X1) pada Kinerja Pegawai (Y)di lingkungan di PT.Mitsui Leasing CapitalAbdul Muis -Jakarta

\section{Pengaruh Motivasi(X2)terhadap Kinerja Pegawai(Y)}

Hipotesys 2(H2) : Di asumsikan ada pengaruh signifikan Motivasi(X2)pada Kinerja Pegawai (Y)di lingkungan di PT.Mitsui Leasing Capital AbdulMuis -Jakarta

3. Pengaruh Disiplin Kerja(X3)terhadap Kinerja Pegawai(Y)

Hipotesys 3(H3) : Di asumsikan ada pengaruh signifikan Disiplin Kerja(X3)pada Kinerja Pegawai (Y) di lingkungan di PT. Mitsui Leasing Capital AbdulMuis -Jakarta

4. Pengaruh Gaya Kepemimpinan (X1),Motivasi (X2)dan Disiplin Kerja(X3)secara bersama-sama(simultan)terhadap Kinerja Pegawai(Y) Hipotesys 4(H4) :

Hipotesys 4(H4) : Di asumsikan ada pengaruh signifikan Gaya Kepemimpinan (X1), Motivasi (X2)dan Disiplin Kerja(X3) secara bersama-sama (simultan)pada Kinerja Pegawai(Y)di lingkungan PT.Mitsui Leasing Capital Abdul Muis -Jakarta.

\section{HASIL PENELITIAN}

\section{A. Hasil Analysis Deskripsi}

1. Variable Gaya Kepemimpinan (X1) 
Presentasi gaya kepemimpinan PT. Mitsui Leasing Capital Abdul Muis Jakarta dengan sampel 100 karyawan mendapatkan response yang baik, berdasarkan response jawaban karyawan dari 12 pertanyaan yang memberi jawaban "Sangat Setuju" sejumlah 221 atau 18,42\%, menjawab "Setuju" sejumlah 870 atau $72,50 \%$, dilanjutkan dengan yang menjawab "RaguRagu" sebanyak 102 atau 8,50\%, sementara jawaban "Tidak Setuju" sejumlah 7 atau $0,58 \%$ serta "Sangat Tidak Setuju" dengan jumlah 0 atau $0,00 \%$.

2. Variabel Motivasi (X2)

Presentasi motivasi PT. Mitsui Leasing Capital Abdul Muis - Jakarta mendapatkan respon jawaban yang cukup baik, hal ini bisa diketahui melalui respon jawaban yang sudah menjawab 8 pernyataan mengenai variable Motivasi, dengan yang sudah menjawab "sangat setuju" sejumlah 122 atau 15,25\%, lalu yang menjawab "setuju" sejumlah 510 atau $63,75 \%$, dilanjutkan oleh yang menyatakan "cukup setuju" sejumlah 133 atau $16,63 \%$, sementara yang menjawab"tidak setuju" sejumlah 35 atau4,38\% dan "sangat tidak setuju" sejumlah 0atau 0,00\%.

3. Variabel Disiplin Kerja (X4)

Presentasi Disiplin PT. Mitsui Leasing Capital Abdul Muis - Jakarta mendapat tanggapan yangbaik, hal ini bisa diketahui melalui jawaban karyawan yang sudah menjawab10 pernyataan mengenai variable Disiplin, yang mana yang menjawab "sangat setuju" berjumlah 155 atau $15,50 \%$, lalu yang menjawab "setuju" berjumlah 647 atau 64,70\%, dilanjutkan dengan yang menjawab "cukup setuju" berjumlah 158 atau $15,80 \%$, sementara yang menyatakan "tidak setuju" sebanyak 40 atau4,00\% dan "sangat tidak setuju" berjumlah 0 atau0,00\%.

4. Variabel Kinerja (Y)

Presentasi Kinerja PT. Mitsui Leasing Capital Abdul Muis - Jakarta mendapat response yang baik dari responden, hal ini bisa diketahui dari hasil quesioner yang telah meresponse 12 pernyataan tentang variable kinerja, yang mana yang menjawab "sangat setuju" berjumlah 220 atau $18,33 \%$, kemudian yang menjawab "setuju" sebanyak 851 atau $70,91 \%$, dilanjutkan dengan yang menjawab "cukup setuju" sebanyak 121 atau $10,08 \%$, sementara yang menyatakan "tidak setuju" sebanyak 8 atau $0,66 \%$ dan "sangat tidak setuju" sebanyak 0 atau $0,00 \%$.

\section{B. Hasil Uji Kualitas Data}

Kualitas suatu datayang sudah diperoleh dari instrumen di evaluasi dengan uji validitas serta uji reliabiltas untuk mengetahui akurasi dari setiap instrument penelitian.

1. Hasil Uji Validitas

Didapatkan melalui mengkorelasikan antaraskor yang didapatkan setiap butirpernyataan dengan skor total maka Validitas instrumen dalampenelitian ini dapat ditentukan. Suatu ukuran yang memperlihatkan tingkatan-tingkatankevalidan ataupun kesahihan 
merupakan definisi Validitas. Jika mampu mengukur apa yangdiinginkan dalam mengungkap datadari variabel yang diteliti maka sebuah instrumen dikatakanvalid. Scara cermat penilaian uji validitasnya yaitu :

a) Jika $\mathrm{r}_{\text {hitung }}>\mathrm{r}_{\text {tabel }} 0,197$ (tarap signifikan5\%) maka disebut valid

b) Jika $r_{\text {hitung }}<r_{\text {tabel }} 0,197$ (tarap signifikan5\%) maka disebut tidak valid. Nilai rtabel diperoleh dengan syarat sebagai berikut :

$$
\begin{array}{ll}
\text { Sampel } & =100 \\
\text { DK }(\text { drajat Kbebasan }) & =\mathrm{n}-2 \\
\text { Tingkat Kpercayaan } & =95 \% \\
\text { Tingkat Ksalahan } & =5 \% \\
\mathrm{~T}_{\text {tabel }}(\alpha, \mathrm{n}-2) & =5 \%, 98 \text { (tabel distribusiR) } \\
\text { Ttabel }(5 \%, 98) & =0,197
\end{array}
$$

2. Hasil Dari Uji Reliabilitas

Suatu indeksyang menunjukan sejauh mana hasil suatu pengukuran dapat di percaya atau handal sebagai alat ukur variabel disebut dengan Uji Reliabilitas. Dalam penelitian ini untukmencari reliabilitas instrumen digunakan rumus Cronbach Alpha. Berikut table hasil reliabilitas instrument, sbb :

\section{Tabel 2 Hasil Uji Reliabilitas Data}

\begin{tabular}{llcc} 
No & \multicolumn{1}{c}{ Variable } & CronbachAlpha & Kesimpulan \\
1 & Gaya Kpemimpinan(X1) & 0,633 & Reliabel \\
2 & Motivasi(X2) & 0,614 & Reliabei \\
3 & Disiplin Kerja(X3) & 0,657 & Reliabel \\
4 & Kinerja Pegawai(Y) & 0,628 & Reliabel
\end{tabular}

Sumber : Data Olahan SPSS 22 (2019)

\section{Pengujian Asumsi Klasik}

\section{Hasil Uji Normalitas}

Distribusi data yangakan dianalysis menyebar normal atau tidak akan diuji dengan Uji normalitas. Apakahdata yang dipakai dalampenelitian ini mempunyai distribusinormal baik secara multivarian ataupun univarian akan diuji dengan Uji Normalitas. Dibawah ini adalah grafik hasil normalitas instrumen yang dipakai sebagai berikut : 


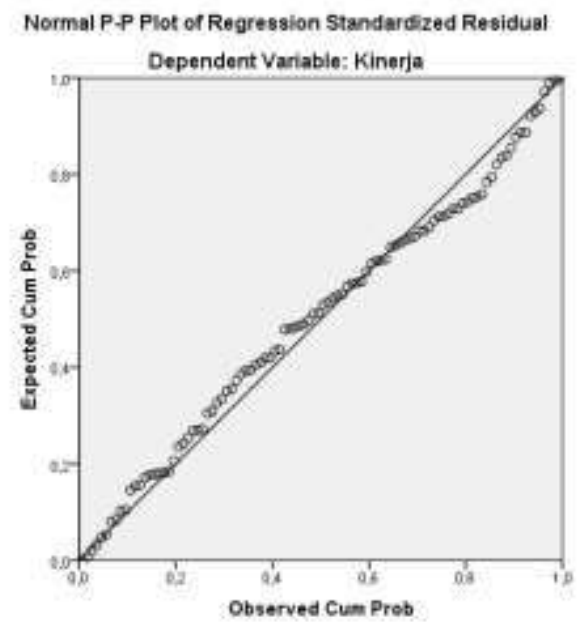

Sumber: Data primer yang diolah dengan SPSSversi 22, tahun 2019 Gambar 2

Grapik Normal P-Pplot Kepemimpinan, Motivasi, serta Disiplin Terhadap Kinerja

Dari gambar tersebut diatas dapat terlihat pola penyebaran data dimana yang berbentuk titik atau lingkaran kecil menyebar mengikuti garis lurus diagonal disekitar diagram dari grafik Normal PP-Plot. Dengan demikian dapat disimpulkan bahwa data residu dari variabel independen Gaya Kepemimpinan (X1), Motivasi (X2) dan Disiplin Kerja (X3) yang diteliti adalah data yang berdistribusi normal. Oleh karena itu uji normalitas menunjukkan terpenuhi asumsi Normalitas.

\section{Uji Multikolinieritas}

Digunakan mengetahuiapakah ada korelasi / hubungan yang kuat antar variable-variable bebas dalam model persamaan regresi merupakan pengertian dari Uji Multikolinieritas. Tidak adanya korelasi antar variable independen merupakan model regresi yang baik. Sebagai pedoman untuk mengetahui hasil korelasi antar variable independen dan juga mengetahui ToleranceValue \& Variance InflationFactor (VIF) dapat dilakukan dengan hipotesa yaitu:

$\mathrm{H}_{\mathrm{o}}$ :Tidak ada multikolinearitas antar variable independen didalam model regresi, jika nilai hubungan antar variable independen $<$ $95 \%$ atau nilai toleransi $>0,10$ persen $\&$ nilaiVIF $<10$.

$\mathrm{H}_{\mathrm{a}}$ :Ada multikolinearitas antarvariable independen didalam model regresi, jika nilai hubungan antar variable independen> 95\% atau nilai toleransi $<0.10$ persen \& nilai VIF $>10$.

Hasil keluaran uji multikolinearitas yaitu sebagai berikut : 
Tabel 3

Uji Multikolinearitas

Coefficients $^{\mathbf{a}}$

\begin{tabular}{|c|c|c|c|c|c|c|c|}
\hline \multirow[b]{2}{*}{ Model } & \multicolumn{2}{|c|}{$\begin{array}{l}\text { Unstandardize } \\
\text { d Coefficients }\end{array}$} & \multirow{2}{*}{$\begin{array}{c}\text { Standardi } \\
\text { zed } \\
\text { Coefficie } \\
\text { nts } \\
\\
\text { Beta }\end{array}$} & \multirow[b]{2}{*}{$\mathrm{t}$} & \multirow[b]{2}{*}{ Sig. } & \multicolumn{2}{|c|}{$\begin{array}{c}\text { Collinearity } \\
\text { Statistics }\end{array}$} \\
\hline & B & $\begin{array}{l}\text { Std. } \\
\text { Error }\end{array}$ & & & & $\begin{array}{l}\text { Tolera } \\
\text { nce }\end{array}$ & VIF \\
\hline $1 \quad$ (Constant) & ,681 & 1,189 & & ,573 &, 568 & & \\
\hline $\begin{array}{l}\text { Gaya } \\
\text { Kepemimpinan }\end{array}$ & ,893 & ,039 & ,868 & 22,619 &, 000 & ,363 & 2,755 \\
\hline Motivasi & ,166 & ,092 & ,163 & 1,801 & 075 & ,066 & 15,246 \\
\hline Disiplin Kerja &,- 021 & ,087 &,- 024 &,- 243 & ,808 &, 054 & 18,354 \\
\hline
\end{tabular}

a. Dependent Variable: Kinerja

Sumber: Data primer yang diolah dengan SPSSversi 22, tahun 2019

Dari tabel coefficient yang didapatkan, dapat diketahui bahwa nilai VIF untuk Kepemimpinan sebesar 2,755, nilai VIF untuk Motivasi sebesar 15,246, dan nilai VIF untuk Disiplin sebesar 18,354. Artinya bahwa, nilai VIF lebih besar dari pada 10. Oleh karena itu, dapat dikatakan bahwa terjadi gejala multikolinieritas di antara variabel bebas.

Untuk mengetahui apakah varian yang sama dimiliki oleh variable pengganggu atau tidak, dapat mengetahuinya dengan melakukan uji Heteroskedastisitas. Dalam model regresi tidak boleh ada suatu gejala Heteroskedastisitas agar dapat memenuhi persyaratan.

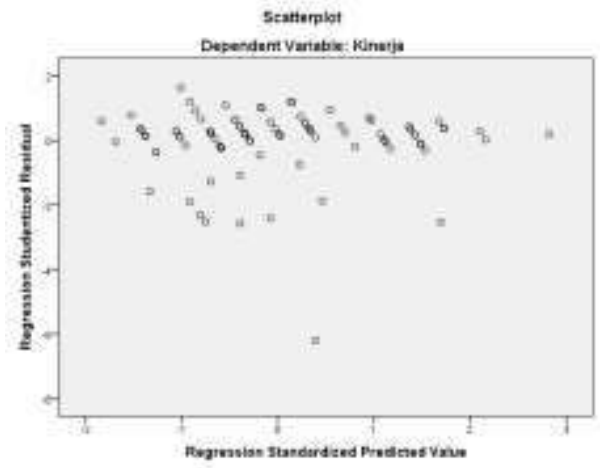

Sumber : Hasil yang diolah dengan SPSS 22

Gambar 3

HasilUji Heteroskesdastisitas

Dapat dilihat gambar scatterplot diatas, diketahui bahwa titik-titik menyebar secara acak, baik di bagian atas angka 0 atau bagian bawah angka 0 dari sumbu vertikal atau sumbu Y. Oleh karena itu dapat disimpulkan bahwa tidak terjadi heteroskedastisitas dalam model regresi ini.

\section{Uji Hipotesis}

\section{Hasil Dari Pengujian Hipotesis Pertama (X1 ke Y)}


a. Uji t

Didalam penelitianini dipakai kriteria signifikansi5\%(0,05)dengan membandingkan $t_{\text {hitung }}$ dengan $t_{\text {tabel }}$ adalah sebagai berikut :

Apabilat $_{\text {hitung }}<\mathrm{t}_{\text {tabel }} \quad:$ Artinya Ho diterima dan $\mathrm{H}_{1} \operatorname{ditolak}(\alpha=5 \%)$

Apabilat $_{\text {hitung }}>t_{\text {tabel }} \quad:$ Artinya Ho ditolak danH $H_{1} \operatorname{diterima}(\alpha=5 \%)$

Hasil dari $t_{\text {tabel }}$ ditentukan dengan memakai rumus :

$\mathrm{Df}=(\mathrm{n}-2)$, maka diperoleh $(100-2)=98$, jadit $_{\text {tabel }}=0,197$

Tabel 4

Hasil Uji t Parsial Hipotesis Pertama

Coefficients $^{\text {a }}$

\begin{tabular}{|l|r|r|r|r|r|}
\hline \multirow{2}{*}{ Model } & \multicolumn{2}{|c|}{$\begin{array}{c}\text { Unstandardized } \\
\text { Coefficients }\end{array}$} & $\begin{array}{c}\text { Standardized } \\
\text { Coefficients }\end{array}$ & \multirow{2}{*}{ Sig. } \\
\cline { 2 - 4 } & \multicolumn{1}{|c|}{ B } & Std. Error & Beta & & \\
\hline 1 (Constant) & 14.060 & 3.627 & & 3.876 & .000 \\
Gaya kepemimpinan & .873 & .048 & .833 & 18.317 & .000 \\
\hline
\end{tabular}

a. Dependent Variable:kinerja

Sumber: Data primer yang diolah dengan SPSSversi 22, tahun 2019

\section{b. Regresi Linear Sederhana}

Gaya Kepemimpinan di PT. Mitsui Leasing Capital Abdul Muis Jakarta berpengaruh terhadap kinerja karyawannya, ini dinyatakan oleh hasil dari uji hipotesis pertama, dalam tabledibawah ini :

\section{Tabel 5}

Hasil Analisis Regresi Linear Hipotesis Pertama Coefficients $^{\text {a }}$

\begin{tabular}{|l|r|r|r|r|r|}
\hline \multirow{2}{*}{ Model } & \multicolumn{2}{|c|}{$\begin{array}{c}\text { Unstandardized } \\
\text { Coefficients }\end{array}$} & $\begin{array}{c}\text { Standardized } \\
\text { Coefficients }\end{array}$ & \multirow{2}{*}{ Sig. } \\
\cline { 2 - 5 } & \multicolumn{1}{|c|}{$\mathrm{B}$} & Std. Error & \multicolumn{1}{c|}{ Beta } & & \\
\hline \multirow{2}{*}{1 (Constant) } & 14.060 & 3.627 & & 3.876 & .000 \\
Gaya kepemimpinan & .873 & .048 & .833 & 18.317 & .000 \\
\hline
\end{tabular}

a. Dependent Variable:kinerja

Sumber: Data primer yang diolah dengan SPSSversi 22, tahun 2019

$\mathrm{Y}=14.060+0.873 \mathrm{X}_{1}$ adalah persamaan regresi linear sesuai dengan table 4 diatas. 
c. Koefisien Determinasi(R-Square)

Tabel 6

Koefisien Determinasi Hipotesis Pertama

Model Summary

\begin{tabular}{|l|r|r|r|r|}
\hline Model & \multicolumn{1}{|c|}{$\mathrm{R}$} & RSquare & $\begin{array}{c}\text { Adjusted R } \\
\text { Square }\end{array}$ & $\begin{array}{r}\text { Std. Errorof } \\
\text { the Estimate }\end{array}$ \\
\hline 1 & $.833^{\mathrm{a}}$ & .694 & .692 & 2.23556 \\
\hline
\end{tabular}

a.Predictors:(Constant),gayakepemimpinan

Sumber: Data primer yang diolah dengan SPSSversi 22, tahun 2019

Dari tabel di atas, didapatkan nilai $R$-Square(koefisien determinasi)sebesar 0,694 oleh karena itu dapat dikatakan bahwa besarnya pengaruh variable gaya kepemimpinan $\left(\mathrm{X}_{1}\right)$ terhadap variable kinerja karyawan(Y) sebesar69,4\% sementara sisanya30,6\% dipengaruhi faktor lain.

2. Hasil Pengujian Hipotesis Kedua (X2 ke Y)

a. Uji t

Tabel 7

Hasil Uji t Parsial Hipotesis Kedua

Coefficients $^{\mathbf{a}}$

\begin{tabular}{|l|r|r|r|r|r|}
\hline \multirow{2}{*}{ Model } & \multicolumn{2}{|c|}{$\begin{array}{c}\text { Unstandardized } \\
\text { Coefficients }\end{array}$} & $\begin{array}{c}\text { Standardized } \\
\text { Coefficients }\end{array}$ & \multirow{2}{*}{ Sig. } \\
\cline { 2 - 5 } & \multicolumn{1}{|c|}{ B } & Std. Error & Beta & & \\
\hline \multirow{2}{*}{1 (Constant) } & 4.210 & 3.244 & & 1.298 & .196 \\
Motivasi & .892 & .038 & .888 & 23.516 & .000 \\
\hline
\end{tabular}

a.Dependent Variable:kinerja

Sumber: Data primer yang diolah dengan SPSSversi 22, tahun 2019

b. Regresi Linear Sederhana

Motivasi di PT. Mitsui Leasing Capital Abdul Muis - Jakarta berpengaruh terhadap kinerja karyawannya, ini dinyatakan oleh hasil dari uji hipotesis kedua, dalam table dibawah ini :

Tabel 8

Hasil Analisis Regresi Linear Hipotesis Kedua

Coefficients $^{\mathbf{a}}$

\begin{tabular}{|l|r|r|r|r|r|}
\hline \multirow{2}{*}{ Model } & \multicolumn{2}{|c|}{$\begin{array}{c}\text { Unstandardized } \\
\text { Coefficients }\end{array}$} & $\begin{array}{c}\text { Standardized } \\
\text { Coefficients }\end{array}$ & \multirow{2}{*}{ Sig. } \\
\cline { 2 - 5 } & \multicolumn{1}{|c|}{ B } & Std. Error & Beta & & \\
\hline \multirow{2}{*}{$\begin{array}{l}\text { (Constant) } \\
\text { Motivasi }\end{array}$} & 4.210 & 3.244 & & 1.298 & .196 \\
& .892 & .038 & .888 & 23.516 & .000 \\
\hline
\end{tabular}

a.Dependent Variable:kinerja

Sumber: Data primer yang diolah dengan SPSS versi 22, tahun 2019

$\mathrm{Y}=4.210+0.892 \mathrm{X}_{2}$ adalah persamaan regresi linear sesuai dengan table 7 diatas. 
c. Koefisien Determinasi(R-Square)

Tabel 9

Koefisien Determinasi Hipotesis Kedua

Model Summary

\begin{tabular}{|l|r|r|r|r|}
\hline Model & \multicolumn{1}{|c|}{$\mathrm{R}$} & RSquare & $\begin{array}{c}\text { Adjusted R } \\
\text { Square }\end{array}$ & $\begin{array}{r}\text { Std. Error of } \\
\text { the Estimate }\end{array}$ \\
\hline 1 & $.888^{\mathrm{a}}$ & .789 & .787 & 1.85671 \\
\hline
\end{tabular}

a.Predictors:(Constant),motivasi

Sumber: Data primer yang diolah dengan SPSSversi 22, tahun 2019

Dari tabel di atas, didapatkan nilai $R$-Square (koefisien determinasi) sebesar

0,789 maka dapat dikatakan bahwa besarnya pengaruh variabel motivasi

$\left(\mathrm{X}_{2}\right)$ terhadap variabel kinerja karyawan $(\mathrm{Y})$ sebesar $78,9 \%$ sedangkan sisanya $21,1 \%$ dipengaruhi faktor lain

\section{Hasil Pengujian Hipotesis Ketiga(X3 ke Y)}

a. Uji t

Tabel 10

Hasil Uji t Parsial Hipotesis Ketiga

Coefficients $^{\mathrm{a}}$

\begin{tabular}{|l|r|r|r|r|r|}
\hline \multirow{2}{*}{ Model } & \multicolumn{2}{|c|}{$\begin{array}{c}\text { Unstandardized } \\
\text { Coefficients }\end{array}$} & $\begin{array}{c}\text { Standardized } \\
\text { Coefficients }\end{array}$ & \multirow{2}{*}{ Sig. } \\
\cline { 2 - 5 } & \multicolumn{1}{|c|}{ B } & Std. Error & Beta & & \\
\hline \multirow{2}{*}{1 (Constant) } & 21.646 & 3.929 & & 5.509 & .000 \\
disiplin kerja & .694 & .046 & .776 & 14.979 & .000 \\
\hline
\end{tabular}

a.Dependent Variable:kinerja

Sumber: Data primer yang diolah dengan SPSSversi 22, tahun 2019

b. Regresi Linear Sederhana

Disiplin Kerja di PT. Mitsui Leasing Capital Abdul Muis - Jakarta berpengaruh terhadap kinerja karyawannya, ini dinyatakan oleh hasil dari uji hipotesis ketiga, dalam table dibawah ini :

\section{Tabel 11}

Hasil Analisis Regresi Linear Hipotesis Ketiga

Coefficients $^{\mathrm{a}}$

\begin{tabular}{|c|c|c|c|c|c|}
\hline \multirow[t]{2}{*}{ Model } & \multicolumn{2}{|c|}{$\begin{array}{c}\text { Unstandardized } \\
\text { Coefficients }\end{array}$} & $\begin{array}{c}\text { Standardized } \\
\text { Coefficients } \\
\end{array}$ & \multirow[t]{2}{*}{$\mathrm{t}$} & \multirow[t]{2}{*}{ Sig. } \\
\hline & B & Std. Error & Beta & & \\
\hline $1 \begin{array}{l}\text { (Constant) } \\
\text { disiplin kerja }\end{array}$ & $\begin{array}{r}21.646 \\
.694 \\
\end{array}$ & $\begin{array}{r}3.929 \\
.046 \\
\end{array}$ & .776 & $\begin{array}{r}5.509 \\
14.979 \\
\end{array}$ & \\
\hline
\end{tabular}

a.Dependent Variable:kinerja

Sumber: Data primer yang diolah dengan SPSS versi22, tahun 2019

$\mathrm{Y}=21.646+0.694 \mathrm{X}_{3}$ adalah persamaan regresi linear sesuai dengan table 10 diatas. 
c. Koefisien Determinasi (R-Square)

Tabel 12

KoefisienDeterminasi Hipotesis Ketiga Model Summary

\begin{tabular}{|l|r|r|r|r|}
\hline Model & R & R Square & $\begin{array}{c}\text { Adjusted R } \\
\text { Square }\end{array}$ & $\begin{array}{l}\text { Std. Error of } \\
\text { the Estimate }\end{array}$ \\
\hline 1 & $.776^{2}$ & .603 & .600 & 2.54745 \\
\hline
\end{tabular}

a.Predictors:(Constant), disiplin kerja

Sumber:Data primer yangdiolah dengan SPSS versi 22, tahun 2019

Dari tabel di atas, didapatkan nilai $R$-Square(koefisien determinasi)sebesar 0,603 maka dapat dikatakan bahwa besarnya pengaruh variable disiplin $\operatorname{kerja}\left(\mathrm{X}_{3}\right)$ terhadap variable kinerja karyawan(Y)sebesar $60,3 \%$ sementara sisanya $39,70 \%$ dipengaruhi faktor lain

\section{Hasil PengujianHipotesis Ke-empat $\left(X_{1}, X_{2}, X_{3}\right.$ ke $\left.Y\right)$}

a. Hasil Regresi Berganda Hipotesis ke-empat

Gaya Kepemimpinan,Motivasi,dan Disiplin Kerja berpengaruh pada Kinerja Pegawai pada PT. Mitsui Leasing Capital Abdul Muis - Jakarta secara simultan, Dan untuk dapat melihat apakah variable Gaya $\operatorname{Kepemimpinan}\left(\mathrm{X}_{1}\right)$,Motivasi $\left(\mathrm{X}_{2}\right)$,dan Disiplin $\operatorname{Kerja}\left(\mathrm{X}_{3}\right)$ memberikan pengaruh yang positif pada variable Kinerja Karyawan(Y) pada PT. Mitsui Leasing Capital Abdul Muis - Jakarta dapat dinyatakan oleh uji regresi berganda hipotesis ke-empat sebagai berikut :

Tabel 13

Hasilpengolahan Regresi Berganda Variabel $\left(X_{1}, X_{2}\right.$ dan $\left.X_{3}\right)$ Coefficients $^{\mathrm{a}}$

\begin{tabular}{|c|c|c|c|c|c|}
\hline \multirow[t]{2}{*}{ Model } & \multicolumn{2}{|c|}{$\begin{array}{l}\text { Unstandardized } \\
\text { Coefficients }\end{array}$} & $\begin{array}{l}\text { Standardized } \\
\text { Coefficients }\end{array}$ & \multirow[t]{2}{*}{$\mathrm{t}$} & \multirow[t]{2}{*}{ Sig. } \\
\hline & B & Std. Error & Beta & & \\
\hline (Constant) & 2.057 & 3.147 & & .654 & .514 \\
\hline Gaya kepemimpinan & .048 & .097 & .045 & .491 & .624 \\
\hline Motivasi & .680 & .095 & .677 & 7.129 & .000 \\
\hline disiplin kerja & .197 & .052 & .220 & 3.814 & .000 \\
\hline
\end{tabular}

a.Dependent Variable:kinerja

Sumber: Data primer yang diolah dengan SPSSversi 22, tahun 2019

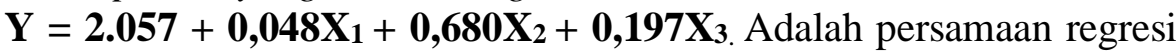
berganda sesuai dengan table 13 diatas.

b. Koefisien Determinasi (R-Square)

Variable independenGaya Kepemimpinan,Motivasi dan Disiplin Kerja terhadap kinerja dapat diukur besar pengaruhnya dengan menggunakan nilai koefisien determinasi $\left(\mathrm{R}^{2}\right)$. Nilai koefisien determinasi $\left(\mathrm{R}^{2}\right)$ digunakan untuk menetahui besarnya pengaruh 
variable Gaya Kepemimpinan, Motivasi dan Disiplin Kerja terhadap kinerja pegawai pada PT.Mitsui Leasing Capital Abdul Muis -Jakarta.

Tabel 14

Koefisien Determinasi Hipotesis Keempat Model Summary

\begin{tabular}{|l|r|r|r|r|}
\hline Model & \multicolumn{1}{|c|}{$\mathrm{R}$} & $\mathrm{R}$ Square & $\begin{array}{c}\text { Adjusted R } \\
\text { Square }\end{array}$ & $\begin{array}{c}\text { Std. Error of } \\
\text { the Estimate }\end{array}$ \\
\hline 1 & $.900^{\mathrm{a}}$ & .810 & .806 & 1.77390 \\
\hline
\end{tabular}

a.Predictors:(Constant), disiplin kerja, gaya kepemimpinan, motivasi

Sumber: Data primer yang diolah dengan SPSSversi 22, tahun 2019

Dari tabel di atas, didapatkan nilai $R$-Square(koefisien determinasi)sebesar 0,810 oleh karena itu bisa dikatakan bahwa variable gaya kepemimpinan,motivasi \& disiplin kerja berpengaruh terhadap variable kinerja karyawan sebesar $81 \%$ sementara sisanya $19 \%$ dipengaruhi oleh faktor lain.

\section{c. Uji Serempak Hipotesis Ke-empat}

Tabel 15

Hasil Uji FSimultan Hipotesis Keempat ANOVA ${ }^{\mathrm{a}}$

\begin{tabular}{|l|r|r|r|r|r|}
\hline Model & \multicolumn{1}{|c|}{$\begin{array}{c}\text { Sum of } \\
\text { Squares }\end{array}$} & df & Mean Square & F & Sig. \\
\hline Regression & 1957.120 & 3 & 652.373 & 207.319 & $.000^{\mathrm{b}}$ \\
1 Residual & 459.420 & 146 & 3.147 & & \\
Total & 2416.540 & 149 & & & \\
\hline
\end{tabular}

a.Dependent Variable:kinerja

b.Predictors:(Constant), disiplin kerja,gaya kepemimpinan,motivasi

Sumber: Data primer yang diolah dengan SPSS versi 22, tahun 2019

Dari table diatas didapatkan hasil $F_{\text {hitung }}=207.319>2,70$ atau( $\left.F_{\text {hitung }}>F_{\text {tabel }}\right)$,hal ini juga diperkuat dengan signifikansi0,000<0,05. Oleh karena itu Ho ditolak dan Ha diterima. Dengan demikian ada pengaruh positif \& signifikan secara simultan antara gaya kepemimpinan,motivasi dan disiplin kerja terhadap kinerja pegawai pada padaPT. Mitsui Leasing Capital Abdul Muis -Jakarta.

\section{E. Pembahasan}

1. Pengaruh Gaya Kepemimpinan $\left(\mathrm{X}_{1}\right)$ terhadap Kinerja(Y) secara parsial

Pengaruh gaya kepemimpinan $\left(\mathrm{X}_{1}\right)$ terhadap kinerja pegawai( $\left.\mathrm{Y}\right)$ yaitu0,694 atau sebesar69.4\% sementara sisanya30.6\% dipengaruhi oleh faktor lain ini menurut hasil statistik. Hal ini memperlihatkan bahwa kinerja pegawai akan meningkat apabila gaya kepemimpinan juga tinggi. 
Dari hasil uji hipotesis didapatkan $t_{\text {hitung }}>t_{\text {tabel }}$ atau $(18.317>0,197)$ hal itu juga diperkuat dengan signifikansi0,000<0,05. Oleh karena itu maka Ho ditolak dan $\mathrm{H}_{1}$ diterima, hal ini mebuktikan bahwa ada pengaruh yang positip \& signifikan secara parsial antara gaya kepemimpinan terhadap kinerja pegawai pada PT.Mitsui Leasing Capital Abdul Muis -Jakarta.

2. Pengaruh Motivasi $\left(\mathrm{X}_{2}\right)$ terhadap $\operatorname{Kinerja}(\mathrm{Y})$ secara parsial

Pengaruh motivasi $\left(\mathrm{X}_{2}\right)$ terhadap kinerja pegawai(Y)yaitu 0,789 atau sebesar $78.9 \%$ sementara sisanya $21.1 \%$ dipengaruhi oleh faktor lain menurut hasil statistik. Hal ini memperlihatkan bahwa kinerja karyawan akan meningkat apabila terdapat motivasi yang baik. Dari hasil uji hipotesis diperoleh $t_{\text {hitung }}>t_{\text {tabel }}$ atau $(23.516>0,197)$ hal itu juga ditunjukkan dengan signifikansi0,000<0,05. Oleh karena itu maka Ho ditolak dan $\mathrm{H}_{1}$ diterima. Hal ini membuktikan bahwa adat pengaruh yang positip \& signifikan secara parsial antara motivasi terhadap kinerja pegawai pada pada PT.Mitsui Leasing Capital Abdul Muis - Jakarta.

3. Pengaruh Disiplin $\operatorname{Kerja}\left(\mathrm{X}_{3}\right)$ terhadap Kinerja(Y)secara parsial

Disiplin $\operatorname{kerja}\left(\mathrm{X}_{3}\right)$ terhadap kinerja pegawai(Y)adalah 0.603 atau sebesar60.3\% sementara sisanya39.70\% dipengaruhi oleh faktor lain menurut hasil statistik. Hal ini membuktikan bahwa kinerja karyawan akan meningkat apabila disiplin kerja juga meningkat. Dari hasil uji hipotesis didapatkant ${ }_{\text {hitung }}>\mathrm{t}_{\text {tabel }}$ atau(14.979 $\left.>0,197\right)$ hal itu juga ditunjukkan dengan signifikansi0,000<0,05.Dengan begitu maka Ho ditolak dan $\mathrm{H}_{1}$ diterima, hal ini membuktikan bahwa terdapat pengaruh yang positif \& signifikan secara parsial antara disiplin kerja terhadap kinerja pegawai pada PT.Mitsui Leasing Capital Abdul Muis - Jakarta.

4. Pengaruh Gaya Kepemimpinan $\left(\mathrm{X}_{1}\right)$,Motivasi( $\left.\mathrm{X}_{2}\right)$ Dan Disiplin $\operatorname{Kerja}\left(\mathrm{X}_{3}\right)$ terhadap Kinerja(Y) secara simultan

Dari hasil perhitungan regresi dalam table diatas, maka didapatkan persamaan regresinyaY $=\mathbf{2 . 0 5 7}+\mathbf{0 , 0 4 8} X_{1}+\mathbf{0 , 6 8 0 X} X_{2}+\mathbf{0 , 1 9 7 X} X_{3}$, Hasil dari analisis regresi ini menyatakan bahwa koefisien dari variable gaya kepemimpinan sebesar0.048, variable motivasi sebesar0,680 dan variable disiplin kerja sebesar0,197. Semuanya bertanda positif ini berarti bahwa semakin baik gaya kepemimpinan, motivasi dan disiplin kerja maka akan semakin baik pula kinerja pegawai pada PT.Mitsui Leasing Capital Abdul Muis - Jakarta. Namun sebaliknya apabila semakin buruk gaya kepemimpinan, motivasi \& disiplin kerja maka akan semakin rendah kinerja karyawan pada PT.Mitsui Leasing Capital Abdul Muis - Jakarta. Kontribusi pengaruh gaya kepemimpinan, motivasi dan disiplin kerja adalah sebesar0,810 atau81\% sementara sisanya sejumlah19\% dipengaruhi oleh faktor lain. Dari pengujian hipotesis didapatkan menggunakan uji satistik, didapatkan $F_{\text {hitung }}=207.319>2,70$ atau $\left(F_{\text {hitung }}>\right.$ $\left.F_{\text {tabel }}\right)$ jadi Ho ditolak danHi diterima. Ini berarti bahwa ada pengaruh positip \& signifikan secara simultan antara gaya kepemimpinan, motivasi dan disiplin kerja terhadap kinerja pegawai pada PT.Mitsui Leasing Capital Abdul Muis - Jakarta. 


\section{KESIMPULAN}

Penulis melakukan penelitian di PT.Mitsui Leasing Capital AbdulMuis Jakarta Pusat, dengan head office di Plaza Bank Index $11^{\text {th }}$ Floor, Suite $1106 \mathrm{Jl}$. M.H. Thamrin Kav 57, Jakarta 10360, perusahaan yang bergerak pada kegiatan pembiayaan keuangan kendaraan bermotor. Berdasarkan hasil pembahasannya penulis memberikan kesimpulan dari hasil penelitian sbb :

1. Gaya kpemimpinan $\left(\mathrm{X}_{1}\right)$ berpengaruh positip \& signifikan terhadap kinerja pegawai(Y)secara parsial di PT.Mitsui Leasing Capital Abdul Muis -Jakarta

2. Motivasi $\left(\mathrm{X}_{2}\right)$ berpengaruh positip \& signifikan terhadap kinerja karyawan(Y) secara parsial di PT.Mitsui Leasing Capital Abdul Muis Jakarta Pusat

3. Disiplin $\operatorname{Kerja}\left(\mathrm{X}_{3}\right)$ berpengaruh positip \& signifikan terhadap kinerja karyawan(Y) secara parsial di PT. Mitsui Leasing Capital Abdul Muis Jakarta Pusat

4. Gaya kpemimpinan $\left(\mathrm{X}_{1}\right)$,Motivasi $\left(\mathrm{X}_{2}\right)$ dan Disiplin $\operatorname{Kerja}\left(\mathrm{X}_{3}\right)$ berpengaruh positip \& signifikan terhadap kinerja karyawan(Y) secara parsial di PT. Mitsui Leasing Capital Abdul Muis -Jakarta Pusat secara simultan

5. Variabel lain yang belum diteliti didalam penelitian ini harus diperhatikan oleh PT.Mitsui Leasing Capital Abdul Muis -Jakarta Pusat, sebab masih banyak variable lain yang dapat mempengaruhi kinerja pegawai agar visi dan misi perusahaan dapat tercapai.

\section{SARAN}

Penulis menyampaikan saran kepada PT. Mitsui Leasing Capital Abdul Muis Jakarta, sebagai berikut :

1. Menyarankan untuk pemimpin di perusahaan lebih peka dan meningkatkan tingkat kepedulian terhadap kebutuhan pegawainya supaya mereka dapat bekerja lebih maksimal lagi.

2. Menyarankan agar perusahaan lebih memperhatikan dan meningkatkan kesejahterahan bagi para karyawannya.

3. Menyarankan agar pemberian sanksi atau hukuman bagi karyawan agar diperhatikan kembali, serta harus memberikan pengarahan dan motivasi yang lebih baik lagi.

4. Agar target perusahaan tercapai, makaperusahaan harus meningkatkan kembali disiplinwaktu serta absensi pegawainya dalam bekerja.

5. Agar lebih nyaman untuk semua karyawan, maka perusahaan segera merenovasi tata ruang di sekitar lingkungan kerja dengan menjagakerapihan dan kebersihannya. 


\section{DAFTAR PUSTAKA}

Buku

Barnawi dan Arifin, M. 2012. Kinerja Guru Profesional. Yogyakarta : Ar-Ruzz Media.

Gaol, CHR. Jimmy L. 2014. A to Z Human Capital (Manajemen Sumber Daya Manusia) Konsep,Teori, dan Pengembangan dalam Konteks Organisasi Publik dan Bisnis. Jakarta: Gramedia Widiasarana.

Fahmi, Irham. 2016. Manajemen Sumber Daya Manusia Teori dan Aplikasi. Bandung: Alfabeta.

Hasibuan S.P, Malayu. 2012. Manajemen Sumber Daya Manusia, Edisi Revisi. Jakarta : Penerbit PT. Bumi Aksara.

Mangkunegara, Anwar, Prabu. 2013. Manajemen Sumber Daya Manusia Perusahaan. Bandung : Penerbit Remaja Rosdakarya.

Marwansyah. 2010. Manajemen Sumber Daya Manusia. Edisi Kedua. Bandung : Alfabeta.

Rivai, Veithzal. 2014. Manajemen Sumber Daya Manusia Untuk Perusahaan. Jakarta : Raja Grafindo Persada.

Siagian, Sondang, P. 2012. Manajemen Sumber Daya Manusia. Jakarta : PT. Bumi Aksara.

Sugiyono. 2009. Metode Penelitian Kuantitatif dan Kualitatif. Bandung : Alfabeta.

Sutrisno, Edy. 2016. Manajemen Personalia Dan Manajemen Sumber Daya Manusia. Jakarta : Prenada Media Group.

Jurnal

Setiyawan dan Waridin. 2012. Pengaruh Disiplin Kerja Karyawan Dan Budaya Organisasi Terhadap KFinerja Di Divisi Radiologi RSUP Dokter Kariadi Semarang. JRBI Vol.No.2, Hal:181-198. 